OPEN ACCESS

Edited by:

Michael G. Surette,

McMaster University, Canada

Reviewed by:

Akira Nakamura,

University of Tsukuba, Japan

Javier Pascual,

Darwin Bioprospecting Excellence,

Spain

${ }^{*}$ Correspondence:

Cha Young Kim

kimcy@kribb.re.kr

Jiyoung Lee

jiyoung1@kribb.re.kr

Specialty section: This article was submitted to

Evolutionary and Genomic

Microbiology,

a section of the journal

Frontiers in Microbiology

Received: 30 June 2021 Accepted: 23 September 2021 Published: 14 October 2021

Citation:

Jiang L, Jeon D, Kim J, Lee CW,

Peng Y, Seo J, Lee JH, Paik JH,

Kim CY and Lee J (2021)

Pyomelanin-Producing

Brevundimonas vitisensis sp. nov., Isolated From Grape (Vitis vinifera L.).

Front. Microbiol. 12:733612.

doi: 10.3389/fmicb.2021.733612

\section{Pyomelanin-Producing Brevundimonas vitisensis sp. nov., Isolated From Grape (Vitis vinifera L.)}

\author{
Lingmin Jiang ${ }^{1}$, Doeun Jeon', Jueun Kim², Chul Won Lee'2, Yuxin Peng ${ }^{1}$, Jiyoon Seo', \\ Ju Huck Lee ${ }^{1}$, Jin Hyub Paik ${ }^{3}$, Cha Young Kim ${ }^{1 *}$ and Jiyoung Lee ${ }^{1 *}$ \\ ${ }^{1}$ Korean Collection for Type Cultures, Biological Resource Center, Korea Research Institute of Bioscience and Biotechnology \\ (KRIBB), Jeongeup, South Korea, 'Department of Chemistry, Chonnam National University, Gwangju, South Korea, \\ ${ }^{3}$ International Biological Material Research Center, Korea Research Institute of Bioscience and Biotechnology (KRIBB), \\ Daejeon, South Korea
}

A novel endophytic bacterial strain, designated GR-TSA-9 ${ }^{\top}$, was isolated from surfacesterilized grape (Vitis vinifera L.). 16S rRNA gene sequence analyses showed that the isolate was grouped within the genus Brevundimonas, displaying the highest similarity with Brevundimonas lenta DS-18 ${ }^{\top}$ (97.9\%) and Brevundimonas kwangchunensis KSL-102 ${ }^{\top}$ $(97.8 \%)$ and less than $97.5 \%$ similarity with other members of Brevundimonas. The strain GR-TSA-9 $9^{\top}$ was a gram negative, rod shaped, facultatively anaerobic, catalase and oxidase positive, and motile bacterium. Its growth occurred at $10-37^{\circ} \mathrm{C}$ (optimally $25-30^{\circ} \mathrm{C}$ ), at $\mathrm{pH}$ 7.0-8.0, and in $\mathrm{NaCl} 0-1 \%$ (optimally $0 \%$ ). It contained ubiquinone-10 as a respiratory quinone, and the major cellular fatty acids (>10\% of the total) were $C_{16: 0}(14.2 \%)$ and summed feature $8\left(\mathrm{C}_{18: 1} \omega 7 \mathrm{c}\right.$ and/or $\left.\mathrm{C}_{18: 1} \omega 6 \mathrm{c}, 65.6 \%\right)$. The polar lipids present in the strain were phosphoglycolipids, phosphatidylglycerol, 1,2-di-O-acyl-3-O-[d-glucopyranosyl$(1 \rightarrow 4)$ - $\alpha$-d-glucopyranuronosyl]glycerol, and unidentified lipids $(L 1, L 2$, and $L 4)$. The strain had one 2,976,716 bp circular chromosome with a $G+C$ content of $66.4 \%$. The digital DNA-DNA hybridization value between strain GR-TSA-9 ${ }^{\top}$ and $B$. lenta DS- $18^{\top}$ was $20.9 \%$, while the average nucleotide identity value was $76.7 \%$. In addition, the $\mathrm{dDDH}$ and ANI values to other members in this genus, whose genome sequences are available, are less than 21.1 and $77.6 \%$. Genome annotation predicted the presence of some gene clusters related to tyrosine degradation and pyomelanin formation. Strain GR-TSA-9T produced a brown melanin-like pigment in the presence of $L$-tyrosine-containing media. The highest pigment production $(0.19 \mathrm{~g} / \mathrm{L})$ was observed in tryptic soy broth with $1.0 \mathrm{mg} / \mathrm{ml} \mathrm{L}$-tyrosine at $25^{\circ} \mathrm{C}$ for 6 days of culture. Biophysical characterization by ultraviolet (UV)-visible spectroscopy, Fourier-transform infrared spectroscopy, and electrospray ionization mass spectrometry confirmed that the pigment was pyomelanin. Additionally, melanized GR-TSA-9 ${ }^{\top}$ cells could protect the cells against UVC exposure. The phylogenetic, genomic, phenotypic, and chemotaxonomic features indicated that strain GR-TSA-9T represents a novel melanin-producing species of Brevundimonas. The type strain was GR-TSA-9 ${ }^{\top}$ $\left(\right.$ KCTC $82386^{\top}=$ CGMCC 1.18820 $)$.

Keywords: phylogenetic analysis, strain GR-TSA-9 ${ }^{\top}$, endophytic bacterium, natural pigments, melanin production 


\section{INTRODUCTION}

The bacterial genus Brevundimonas was reclassified from the genus Pseudomonas as a member of the family Caulobacteraceae based on a polyphasic approach; type strains Brevundimonas diminuta ATCC $11568^{\mathrm{T}}$ and Brevundimonas vesicularis ATCC $11426^{\mathrm{T}}$ were proposed at the same time (Segers et al., 1994). Several Caulobacter species, such as C. bacteroides, C. intermedius, C. subvibrioides, C. variabilis, and Caulobacter subspecies, such as C. henricii subsp. aurantiacus, C. subvibrioides subsp. albus, as well as Mycoplana species, such as Mycoplana bullata (Abraham et al., 1999), were subsequently transferred to the genus Brevundimonas. As of April 2021, 32 species have been reported in this genus. ${ }^{1}$ Members of the genus Brevundimonas survive in diverse environments, including deep-subsea floor sediment (Tsubouchi et al., 2013), different soil sources (Yoon et al., 2006, 2007; Pham et al., 2016), the sea (Fritz et al., 2005), activated sludge (Ryu et al., 2007; Qu et al., 2019; Lee et al., 2020), humans (Sofer et al., 2007; Estrela and Abraham, 2010), aquatic habitats (Abraham et al., 2010), and floor sediments (Tsubouchi et al., 2013, 2014). The genus Brevundimonas has been reported to be a growth promoter in agriculture (Singh et al., 2016; Naqqash et al., 2020) and a bioremediation tool for the removal of copper (Rathi and Yogalakshmi, 2021), dimethachlon (Zhang et al., 2020), and arsenic toxicity (Singh et al., 2016). Furthermore, some species of this genus were found to be opportunistic pathogens isolated from clinical samples (Chandra et al., 2017; Ryan and Pembroke, 2018). Members of this genus are characterized as gramnegative, facultatively anaerobic or aerobic, rod-shaped, oxidase- and catalase-positive, non-fermenting bacteria with a relatively high DNA $\mathrm{G}+\mathrm{C}$ content (Wang et al., 2012; Qu et al., 2019; Lee et al., 2020). Ubiquinone 10 (Q-10) is a major isoprenoid quinone. Interestingly, Brevundimonas sp. SGJ was reported to produce L-dihydroxylphenylalanine (DOPA) melanin, which is predominantly an indolic polymer that is widely used in cosmetics, agriculture, and medicine (Surwase et al., 2012a,b, 2013).

Melanin, a high-molecular-weight polymer, is a ubiquitous natural pigment widely encountered in all organisms. Most microbial melanins are formed through the transformation of either tyrosine (3, 4-DOPA pathway) or malonyl-coenzyme A (dihydroxynaphthalene pathway), which is facilitated by different sets of enzymes. The melanin precursor tyrosine is converted to L-DOPA by tyrosinase (EC 1.14.18.1) and laccase (EC 1.10.3.2; Pavan et al., 2020). The second pathway for melanin synthesis is, endogenously produced malonyl-CoA is catalyzed by polyketide synthases and converted to 1,3,6,8-tetrahydroxynaphthalene and polymerized to dihydroxynaphthalene melanin (Pavan et al., 2020). The third pathway for melanin synthesis is the homogentisate pathway, wherein 4-hydroxyphenylpyruvate dioxygenase ( $h p p D$; EC 1.13.11.27) is the most critical enzyme for transfer to homogentisic acid (HGA) melanins (or pyomelanin), and the $h p p D$ gene plays a vital role in the HGA pathway (Singh et al., 2018).

${ }^{1}$ https://lpsn.dsmz.de/genus/brevundimonas
In the present study, a new strain, GR-TSA- $9^{\mathrm{T}}$, isolated from grapes was characterized as a novel species of the genus Brevundimonas based on the results obtained from a polyphasic taxonomic study. This strain is of interest because it can synthesize melanin. Whole-genome analysis was used to investigate the underlying pathways involved in pyomelanin biosynthesis mediated by the homogentisate pathway. Here, we present a novel species of the genus Brevundimonas, $B$. vitisensis sp. nov., with respect to taxonomy, genome analysis, and identification of pyomelanin production.

\section{MATERIALS AND METHODS}

\section{Bacterial Strains}

Grapes were collected from Jeongeup $\left(35^{\circ} 424.176^{\prime}\right.$ and $\left.126^{\circ} 547.308^{\prime}\right)$, and $5 \mathrm{~g}$ grape was surface-sterilized with $1.05 \%$ sodium hypochlorite for $10 \mathrm{~min}$, followed by rinsing five times with sterile distilled water. After grinding in $20 \mathrm{ml}$ sterile water, $100 \mu$ of each sample was spread onto tryptic soy agar (TSA) medium and incubated at $25^{\circ} \mathrm{C}$ for 4 days. Single colonies were obtained and subsequently streaked on fresh TSA medium. One grayish white, circular, smooth, opaque, and flat isolate, designated as GR-TSA-9 ${ }^{\mathrm{T}}$, was selected for further taxonomic study and preserved in sterile skimmed milk $(10 \%, \mathrm{w} / \mathrm{v})$ at $-80^{\circ} \mathrm{C}$. The strain was deposited at the Korean Collection for Type Cultures (KCTC) and the China General Microbiological Culture Collection (CGMCC) as KCTC $82386^{\mathrm{T}}$ and CGMCC $1.18820^{\mathrm{T}}$, respectively. Unless otherwise stated, the cells were grown on TSA medium at $25^{\circ} \mathrm{C}$ for 5 days for subsequent tests.

\section{Phenotypic and Biochemical Characterization}

Cell morphology was observed using scanning electron microscopy (Quanta 250 FEG) at the KRIBB Microscopy Core Facility. A Gram staining kit (Difco) was used according to the manufacturer's instructions. Cells were grown on soft King B (peptone $20 \mathrm{~g} / \mathrm{L}, \mathrm{MgSO}_{4} 7 \mathrm{H}_{2} \mathrm{O} 1.5 \mathrm{~g} / \mathrm{L}$, and $\mathrm{K}_{2} \mathrm{HPO}_{4} 1.5 \mathrm{~g} / \mathrm{L}$ ) medium containing agar $(0.3,0.5$, and $1.5 \% \mathrm{w} / \mathrm{v})$ for 5 days to test swimming, swarming, and twitching motilities (Belgini et al., 2014). To determine catalase activity, bubble production was observed after adding 3\% (v/v) hydrogen peroxide solution to fresh cells (Lee and Jeon, 2017). An oxidase reagent kit (bioMérieux) was used to determine oxidase activity. Growth of strain GR-TSA- $9^{\mathrm{T}}$ was observed using different media, namely nutrient agar (NA, beef extract $3 \mathrm{~g} / \mathrm{L}$, peptone $5 \mathrm{~g} / \mathrm{L}$, and agar $15 \mathrm{~g} / \mathrm{L}$ ), potato dextrose agar (PDA), Luria-Bertani agar (LB), TSA, marine agar 2216 (MA), reasoner's 2A agar (R2A), and reinforced clostridial agar (RC). Various temperatures of 4 , $10,15,20,25,30,37,40,45$, and $60^{\circ} \mathrm{C}$ were assessed for optimal growth. Tryptic soy broth (TSB) with different $\mathrm{pH}$ values ranging from 3.0 to 12.0 was prepared using $10 \mathrm{mM}$ Tris- $\mathrm{HCl}$ (Hwang et al., 2018) and adjusted with $1 \mathrm{~N} \mathrm{HCl}$ and $\mathrm{NaOH}$, while salt concentrations ranging from 0 to $15 \%(\mathrm{w} / \mathrm{v}$; $1 \%$ concentration increments; Lee et al., 2019) were prepared to determine the optimal $\mathrm{pH}$ and salt concentration, respectively. 
Optical density at $600 \mathrm{~nm}\left(\mathrm{OD}_{600}\right)$ was measured using an Optizen POP UV/VIS spectrophotometer (Optizen) to monitor the $\mathrm{pH}$ range and $\mathrm{NaCl}$ tolerance. The anaerobic growth was tested by incubating strain GR-TSA- $9^{\mathrm{T}}$ on TSA medium in an anaerobic chamber (Coy Scientific) filled with $86 \% \mathrm{~N}_{2}, 7 \%$ $\mathrm{CO}_{2}$, and $7 \% \mathrm{H}_{2}$ at $25^{\circ} \mathrm{C}$ for 7 days. Other biochemical features, such as enzymes, were tested using API 20NE (bioMérieux) or API ZYM with $\mathrm{NaCl} 0.85 \%$ medium (bioMérieux) according to the manufacturer's protocol.

\section{S rRNA Gene Sequence Analysis}

The almost-complete 16S rRNA gene sequence of strain GR-TSA- $9^{\mathrm{T}}$ was amplified by polymerase chain reaction using the universal primers $27 \mathrm{~F}$ and $1492 \mathrm{R}$ (Lane, 1991), and sequencing was performed using primers $27 \mathrm{~F} / 1492 \mathrm{R}$ and $518 \mathrm{~F}$ (5'-CCAGCAGCCGCGGTAATACG-3') and 800R (5'-TACCAGGGTATCTAATCC-3'). The nearly full-length $16 \mathrm{~S}$ rRNA gene was 1394 nucleotides in length and was compared to the corresponding sequences of the type strains obtained from the EzBioCloud server (Yoon et al., 2017). ${ }^{2}$ BioEdit (V.7.0.5) was used to perform multiple sequence alignments using all validly published members of the family Caulobacteraceae. Phylogenetic trees were constructed using the neighbor-joining $(\mathrm{NJ})$, minimum evolution (ME), and maximum likelihood (ML) algorithms with 1,000 bootstrap iterations in the Molecular Evolutionary Genetics Analysis version 7.0 program (Kumar et al., 2016). Evolutionary distances for the NJ, ME, and ML analyses were calculated using Kimura's two-parameter model.

\section{Genomic Sequencing and Annotation}

Genomic DNA of strain GR-TSA-9 ${ }^{\mathrm{T}}$ was isolated using a genomic DNA purification kit (MGmed, Republic of Korea). The quantity and quality of the extracted genomic DNA were measured using PicoGreen and Nanodrop (ratio A260/A280). Whole-genome sequencing was performed at the Macrogen facility (Macrogen, Korea) on the PacBio RSII (Pacific Biosciences, Inc.) and the Illumina sequencing platform and assembled using SMRT Portal (version 2.3) de novo assembler. Potential contamination of the genome sequence was verified using ContEst16S (Lee et al., 2017). ${ }^{3}$ The assembled sequences were annotated using the National Center for Biotechnology Information Prokaryotic Genome Annotation Pipeline (PGAP) and the Rapid Annotation Subsystem Technology (RAST) server with the SEED database (Tatusova et al., 2016). Metabolic pathways were reconstructed using BlastKOALA based on the Kyoto Encyclopedia of Genes and Genomes pathway database (Kanehisa et al., 2016). The digital DNA-DNA hybridization ( $\mathrm{dDDH})$ and average nucleotide identity (ANI) values between strain GR-TSA-9 ${ }^{\mathrm{T}}$ and several closely related strains were calculated using the Genome-toGenome Distance Calculation web server ${ }^{4}$ using the BLAST method and recommended formula 2 (Meier-Kolthoff et al., 2013) as well as an ANI calculator. ${ }^{5}$ The orthoANI values among

${ }^{2} \mathrm{http}: / /$ www.ezbiocloud.net

${ }^{3}$ https://www.ezbiocloud.net/tools/contest16s

${ }^{4} \mathrm{http}: / /$ ggdc.dsmz.de/distcalc2.php

${ }^{5}$ https://www.ezbiocloud.net/tools/ani the closely related strains were calculated using the standalone Orthologous Average Nucleotide Identity (OAT) software (Lee et al., 2016). Whole-genome sequences of closely related strains publicly available at NCBI GenBank were collected, and a whole-genome-based phylogenetic tree was constructed using the up-to-date bacterial core gene set and pipeline as described by $\mathrm{Na}$ et al. (2018). Briefly, the 92 core genes were extracted from genomes using Prodigal v2.6.3 (Hyatt et al., 2010) and hmmsearch v3.1b2 (Eddy, 2011). Predicted coding sequences (CDS) of 92 core genes were aligned by using Multiple Alignment using Fast Fourier Transform (MAFFT) for alignments (ver. 7.310; Katoh and Standley, 2013). Then, the phylogenomic tree was inferred by using the FastTree (Price et al., 2010) and viewed using MEGA v7.0 (Kumar et al., 2016). The branch support inference was based on 100 nonparametric bootstrap replicates, and the branch supports for the phylogenomic tree were evaluated using gene support index (GSI).

\section{Chemotaxonomic Characterization}

For fatty acid methyl ester analysis, cells grown for 3 days on TSA were extracted according to the instructions of the standard MIDI (Sherlock Microbial Identification System version 6.0), and cellular fatty acid content was analyzed by gas chromatography (Model 6890 N; Agilent) using the Microbial Identification software package (Sasser, 2006). Freeze-dried cells $(100 \mathrm{mg})$ were used to extract isoprenoid quinones using a chloroform-to-methanol $(2: 1, \mathrm{v} / \mathrm{v})$ mixture, followed by analysis using thin-layer chromatography as described by Collins et al. (1980). Subsequent analysis was performed using reverse-phase high-performance liquid chromatography with ultraviolet (UV) absorbance detection at $270 \mathrm{~nm}$. Polar lipids were extracted from $100 \mathrm{mg}$ of freeze-dried cells with a chloroform/methanol mixture $(1: 2, \mathrm{v} / \mathrm{v})$ and then identified by two-dimensional thinlayer chromatography on Kieselgel 60 F254 plates (silica gel, $10 \mathrm{~cm} \times 10 \mathrm{~cm}$; Merck). In addition, $0.2 \%$ ninhydrin (SigmaAldrich), $\alpha$-naphthol, molybdenum blue (Sigma-Aldrich), 4\% phosphomolybdic acid reagent, and Dragendorff's solution were sprayed onto the plates to detect amino group-containing lipids, sugar-containing lipids, phosphorus-containing lipids, total lipids, and quaternary nitrogen-containing lipids, respectively.

\section{Production and Purification of the Microbial Pigment}

The melanin-producing ability of strain GR-TSA- $9^{\mathrm{T}}$ was confirmed by growth on TSA medium supplemented with 0 and $10 \mathrm{mg} / \mathrm{ml}$ of L-tyrosine followed by incubation at $25^{\circ} \mathrm{C}$. Production was performed in TSB consisting of $0,0.2,0.4,0.6,0.8$, and $1.0 \mathrm{mg} / \mathrm{ml}$ L-tyrosine, and after inoculation with $1 \mathrm{ml}$ of the cell suspension $\left(\mathrm{OD}_{600}=1.0\right)$ in $100 \mathrm{ml} \mathrm{TSB}$, shaking at $25^{\circ} \mathrm{C}$ and $150 \mathrm{rpm}$ for 1-7 days, and melanin production in the broth was measured at $\mathrm{OD}_{400}$ using the standard synthetic melanin (Sigma-Aldrich, M8631) calibration curve method (Singh et al., 2018). Melanin was purified as previously described (El-Naggar and El-Ewasy, 2017). Briefly, the supernatant was centrifuged at $8,000 \mathrm{rpm}$ to remove the cells, followed by adjustment of the $\mathrm{pH}$ of the supernatant to 2.0 using $6 \mathrm{M} \mathrm{HCl}$; the samples were then allowed 
to stand for $4 \mathrm{~h}$ and centrifuged at $8,000 \mathrm{rpm}$ to collect the precipitate. The melanin pellets were washed with distilled water three times and then centrifuged at $8,000 \mathrm{rpm}$ for $10 \mathrm{~min}$ to obtain melanin. The purified melanin was freeze-dried for further use. In vitro-synthesized pyomelanin was produced by autooxidation of $10 \mathrm{mM}$ HGA (Sigma-Aldrich, H0751) solution at pH 10 with constant stirring for 3 days as described by SchmalerRipcke et al. (2009).

\section{UV-Visible Spectroscopy and Fourier- Transform Infrared Spectroscopy}

To analyze the pigment content of GR-TSA- $9^{\mathrm{T}}$, purified melanin was dissolved in $0.5 \mathrm{M} \mathrm{NaOH}$ solution, and the absorption value was recorded in the wavelength range of $200-1000 \mathrm{~nm}$ with a UV-visible spectrophotometer (Thermo Fisher Scientific, USA) by comparing it to a synthetic melanin standard. FT-IR spectroscopy was performed at the Center for Instrumental Analysis, Korea Basic Science Institute, Busan, Republic of Korea. The samples were pressed into disks under vacuum using a KBrpress. The FT-IR spectra of the $\mathrm{KBr}$ discs were recorded on an FT-IR Vertex 80v spectrophotometer (Bruker, USA). The spectra were read in the wavenumber region of $400-4000 \mathrm{~cm}^{-1}$.

\section{Electrospray Ionization Mass Spectrometry}

Mass spectrometry analysis was performed using an API 32000 mass spectrometer (AB SCIEX, USA). Samples were dissolved in $1 \mathrm{M} \mathrm{NaOH}$ solution and then diluted with 50:50 methanol/ water. The optimized mass spectrometry parameters were as follows: curtain gas, 10; spray voltage, 4200; ion source gas, $20 \mathrm{psi}$; and flow rate, $10 \mu \mathrm{l} / \mathrm{ml}$. Full spectra were collected in the $m / z$ range of $50-1800$ in the positive ion mode.

\section{UVC Exposure and Sensitivity Tests}

GR-TSA-9 ${ }^{\mathrm{T}}$ cells were cultured on TSA (non-melanized cells) and TSA with $10 \mathrm{mg} / \mathrm{ml} \mathrm{L}$-tyrosine (melanized cells) at $25^{\circ} \mathrm{C}$ for $48 \mathrm{~h}$. The cells were washed twice with $1 \times$ phosphatebuffered saline. Next, $5 \times 10^{7}$ cells were irradiated with UVC $(254 \mathrm{~nm})$ at $450 \mathrm{~mJ} / \mathrm{cm}$, and $10 \mu \mathrm{l}$ of aliquots from tenfold serial dilutions was spotted on TSA plates. All plates were incubated at $25^{\circ} \mathrm{C}$ for 3 days. The experiments were repeated at least twice, with similar results.

\section{RESULTS AND DISCUSSION}

\section{Phenotypic and Biochemical Characterization}

Strain GR-TSA $-9^{\mathrm{T}}$ grew well on LB, TSA, MA, NA, and R2A (optimum TSA and LB) but not on RC and PDA. Growth occurred at $10-37^{\circ} \mathrm{C}$ (optimal $25-30^{\circ} \mathrm{C}$ ), in $0-1 \%(\mathrm{w} / \mathrm{v})$ of $\mathrm{NaCl}$ (optimum $0 \%$ ), and at $\mathrm{pH} 7.0-8.0$. Cells were rod shaped $(0.2-0.3 \mu \mathrm{m}$ in width and $0.9-2.6 \mu \mathrm{m}$ in length) with flagella (Supplementary Figure 1), gram negative, facultatively anaerobic, motile by swimming and twitching, catalase weakly positive, and oxidase positive. Other characteristics of strain GR-TSA-9 ${ }^{\mathrm{T}}$, which is different from closely related strains, are shown in Table 1.

\section{Phylogenetic Analyses}

The almost-complete $16 \mathrm{~S}$ rRNA gene amplicon of strain GR-TSA-9 $9^{\mathrm{T}}$ contained 1394 nucleotides and has been submitted to GenBank (accession number: MW442968.1). Based on 16S rRNA gene sequence analysis, strain GR-TSA-9 ${ }^{\mathrm{T}}$ appeared to belong to the genus Brevundimonas and was closely related to B. lenta DS- $18^{\mathrm{T}}$ (97.9\%), B. kwangchunensis KSL-102 ${ }^{\mathrm{T}}(97.8 \%)$, and $B$. aurantiaca DSM $4731^{\mathrm{T}}(97.5 \%)$, whereas it shared less than $97.5 \%$ similarity with other related species. Based on the novel species recognition threshold of $98.6 \%$ (Kim et al., 2014), strain GR-TSA- $9^{\mathrm{T}}$ was regarded as a novel species in the genus Brevundimonas. A phylogenetic tree was reconstructed using the NJ, ME, and ML methods. The results of these analyses suggest that strain GR-TSA-9 $9^{\mathrm{T}}$ belongs to the genus Brevundimonas. The genera Asticcacaulis, Caulobacter, and Phenylobacterium formed independent and monophyletic branches (Figure 1). Moreover, B. fluminis LA-55 ${ }^{\mathrm{T}}$, B. viscosa CGMCC $1.10683^{\mathrm{T}}$, B. kwangchunensis KSL-102 ${ }^{\mathrm{T}}$, B. lenta DS- $18^{\mathrm{T}}$, and $B$. diminuta AJ $2068^{\mathrm{T}}$, the type species of genus Brevundimonas, were used to compare phenotypic properties and for chemotaxonomic analyses based on 16S rRNA similarity and phylogenetic tree analysis.

\section{Genome Properties and Genetic Relatedness}

The genome of strain GR-TSA-9 ${ }^{\mathrm{T}}$ was assembled using the SMRT Portal (version 2.3) de novo assembler, which is a single circular chromosome of 2,976,716bp in size (the N50 value was $13,858 \mathrm{bp}$ ), with a coverage of $389 \mathrm{X}$. By comparing two copies of the 16S rRNA gene fragment from the whole-genome sequence, a contaminating DNA sequence was not present in the genome assembly. The genomic GC content of GR-TSA-9 ${ }^{\mathrm{T}}$ was $66.4 \%$, which was similar to that of other type strains in the genus Brevundimonas. According to the PGAP annotation, there were 2940 protein-coding genes and 56 RNA genes, including two 5S rRNA genes, two $16 \mathrm{~S}$ rRNA genes, two $23 \mathrm{~S}$ rRNA genes, four ncRNAs, and 46 tRNA genes. Cluster orthologous group (COG) annotation results showed that the functional categories of most coding sequences were classified as unknown (28.6\% of total assigned COGs), general function prediction only (9.1\% of the total assigned COGs), and amino acid transport and metabolism $(5.8 \%$ of the total assigned COGs; Supplementary Figure 2).

The $\mathrm{dDDH}$ value between strain GR-TSA-9 ${ }^{\mathrm{T}}$ and the closest species $B$. lenta DS- $18^{\mathrm{T}}$ was $20.9 \%$, while the ANI value was $76.7 \%$. OrthoANI values based on the entire genome (Supplementary Figure 3) were 72.8-77.6\% for the most closely related strains. Thus, strain GR-TSA- $9^{\mathrm{T}}$ was considered a distinct species of the genus Brevundimonas, considering the values obtained were significantly lower than the proposed $\mathrm{dDDH}$ $(<70 \%)$ and ANI cutoff (95-96\%) values for bacterial species delineation (Chun et al., 2018). The 92 core gene set-based 
TABLE 1 | Differential physiological and biochemical comparison of strain GR-TSA-9T and closely related type strains.

\begin{tabular}{|c|c|c|c|c|c|c|}
\hline Characteristics & 1 & 2 & 3 & 4 & 5 & $6^{e}$ \\
\hline Isolation source & Grape & Alkaline soila & River $^{\mathrm{b}}$ & Saline soil ${ }^{c}$ & Soil & Fresh water \\
\hline Colony color & Grayish white, & Grayish yellow & Ivory-colored ${ }^{\mathrm{b}}$ & White ${ }^{c}$ & Grayish yellow ${ }^{d}$ & White to creamy \\
\hline Oxygen requirement & Facultatively aerobic & Aerobic $^{a}$ & Facultatively aerobic $^{b}$ & Aerobic $^{c}$ & Aerobic $^{d}$ & Aerobic \\
\hline Colony shape & $\begin{array}{c}\text { Circular, smooth, } \\
\text { opaque, flat elevation }\end{array}$ & $\begin{array}{c}\text { Circular, smooth, } \\
\text { glistening, slightly } \\
\text { convex }^{\mathrm{a}}\end{array}$ & $\begin{array}{l}\text { Circular, convex, } \\
\text { opaque }^{b}\end{array}$ & $\begin{array}{l}\text { Circular, smooth, } \\
\text { slightly convex }\end{array}$ & $\begin{array}{l}\text { Circular, convex, } \\
\text { glistening, sticky }\end{array}$ & $\begin{array}{l}\text { Smooth, raised, } \\
\text { white to creamy }\end{array}$ \\
\hline Catalase & w & $t^{\mathrm{a}}$ & $+^{\mathrm{b}}$ & $+^{c}$ & $+^{d}$ & + \\
\hline Melanin production & + & + & - & + & + & - \\
\hline Cell size $(\mu \mathrm{m})$ & $0.2-0.3 \times 0.9-2.6$ & $0.4-0.6 \times 1.0-3.0^{a}$ & $0.2-0.5 \times 1.0-3.0^{\mathrm{b}}$ & $0.4-0.6 \times 0.9-2.5^{c}$ & $0.3-0.5 \times 0.6-3.5^{d}$ & $0.5 \times 1.0-4.0$ \\
\hline \multicolumn{7}{|l|}{ Growth at: } \\
\hline Temperature range $\left({ }^{\circ} \mathrm{C}\right)$ & 10-37 (25-30) & 10-36 (30) & $15-40$ & $10-36(28-30)$ & $4-34(25)$ & 35 \\
\hline $\mathrm{NaCl}$ range $(\%, w / v)$ & $0-1(0)$ & $0-2(0)$ & 0-2 & $0-3(0)$ & $0-1(0)$ & 7.0 \\
\hline $\mathrm{pH}$ range & $7-8(7)$ & $6-9(7-8)$ & $6.0-8.0$ & $5.5-11(7-8)$ & $6-9.5(0.5-7.0)$ & - \\
\hline \multicolumn{7}{|l|}{ API 20NE } \\
\hline Nitrate reduction & - & - & - & + & - & - \\
\hline$\beta$-galactosidase & + & - & - & - & - & ND \\
\hline Glucose Assimilation & - & + & - & - & + & - \\
\hline Maltose & - & + & - & - & + & - \\
\hline Malate & - & + & + & - & - & - \\
\hline Citrate & - & + & + & - & - & - \\
\hline \multicolumn{7}{|l|}{ API ZYM } \\
\hline Valine arylamidase & w & w & + & + & w & - \\
\hline Cystine arylamidase & w & - & - & w & w & - \\
\hline$\alpha$-chymotrypsin & w & w & w & + & w & + \\
\hline Acid phosphate & - & + & - & w & + & ND \\
\hline $\begin{array}{l}\text { Naphthol-AS-BI- } \\
\text { phosphohydrolase }\end{array}$ & w & + & w & + & w & ND \\
\hline$\alpha$-glucosidase & + & + & + & + & w & - \\
\hline
\end{tabular}

Strains: 1, Brevundimonas vitisensis GR-TSA-9'; 2, B. kwangchunensis KCTC 12380'; 3, B. fluminis KCTC 72717'; 4, B. viscosa JCM 17426'; 5, B. lenta KCTC 12871'; and 6,

B. diminuta AJ $2067^{T}$. All data are from the present study unless indicated otherwise. +, positive; w, weakly positive; -, negative; and ND, not detected.

ayoon et al. (2006).

bee et al. (2020).

"Wang et al. (2012).

'Yoon et al. (2007).

eSegers et al. (1994).

phylogenetic tree also supported strain GR-TSA $-9^{\mathrm{T}}$ forming a phylogenetic lineage within the genus Brevundimonas, consistent with the 16S rRNA-based phylogenetic tree (Figure 2).

\section{Genome-Derived Features of Strain GR-TSA-9'}

Genome annotation was performed using the RAST server and BlastKOALA to reconstruct the metabolic pathway, and the following sections were predicted from genome sequences.

\section{Motility}

Genes related to the motility subsystem were detected in the whole genome, including basal-body rod protein $\mathrm{FlgB}$, FlgC, and FlgD; flagellar hook-basal body complex protein FliE; flagellar motor switch protein FliM and FliN; flagellar L-ring protein FlgH; flagellar biosynthesis protein FlhB; FlhR and FlhA; and flagellar motor rotation proteins MotA and MotB. These data are consistent with the motility test results.

\section{Respiration}

Ferredoxin reductase, one of the anaerobic respiratory reductases, was annotated in the whole genome, which explains the fact that the strain can grow under anaerobic conditions. Among all respiration-related genes, most are related to electron-donating and electron-accepting reactions, followed by ATP synthases, biotin synthesis, the quinone oxidoreductase family, biogenesis of cytochrome $\mathrm{C}$ oxidases, biogenesis of c-type cytochromes, soluble cytochromes, and functionally related electron carriers.

\section{Stress Response}

Osmotic stress-related genes encoding enzymes involved in the synthesis of osmoregulated periplasmic glucans and osmoregulation were found in the whole genome, and no gene related to heat shock, cold shock, or salt stress was observed in the whole genome. These results explain why the strain grows at a limited temperature and salinity range.

\section{Glycerophospholipid and Glycerolipid Metabolism}

The enzymes for glycerolipid and glycerophospholipid synthesis were found in the whole genome; genes encoding PG biosynthesis enzymes, such as phosphatidate cytidylyltransferase (EC 2.7.7.41) and CDP-diacylglycerol-glycerol-3-phosphate 3-phosphatidyltransferase (EC 2.7.8.5), and phosphatidylcholine biosynthesis enzymes, such as glycerol-3-phosphate 


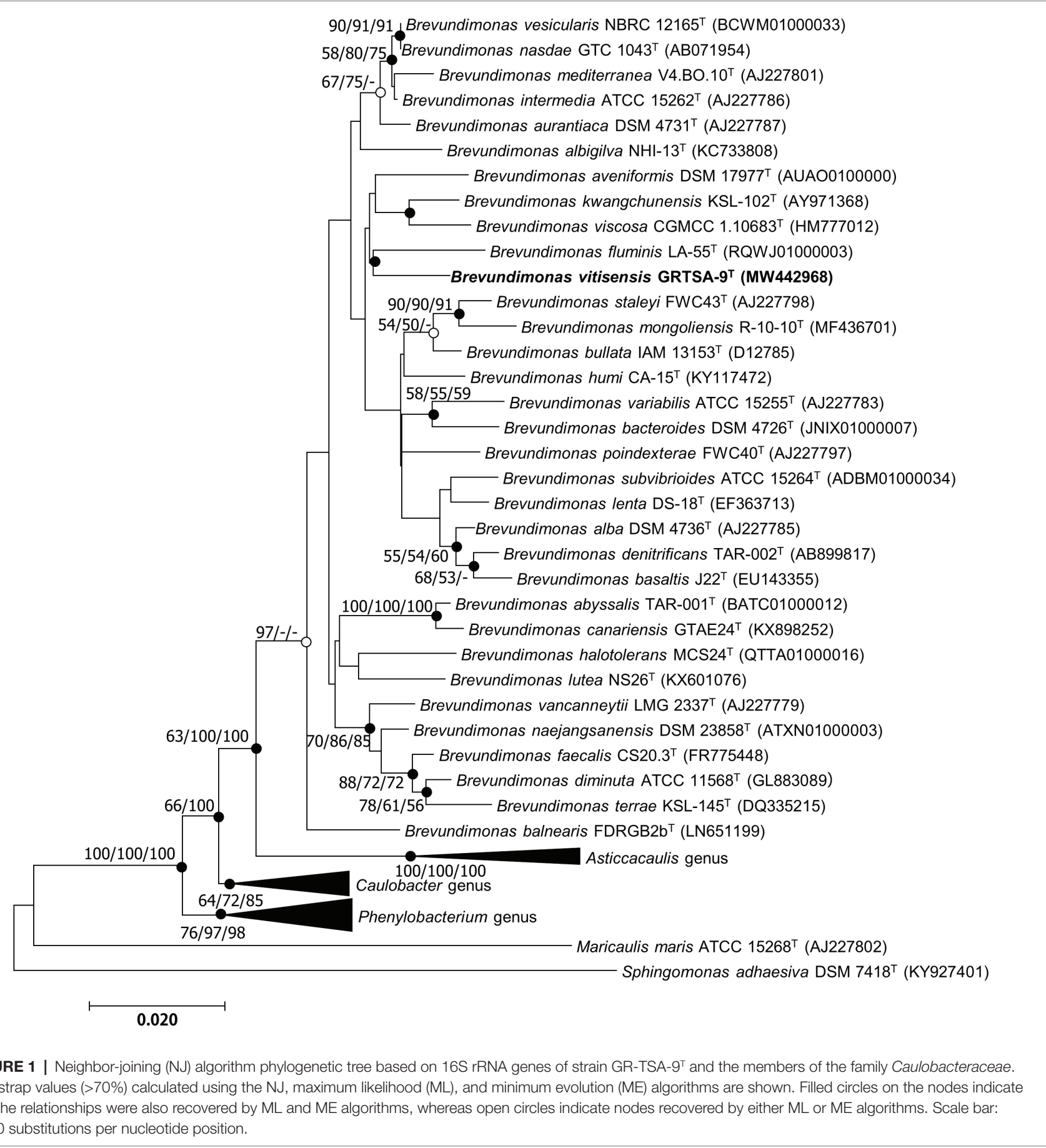

dehydrogenase (EC 1.1.5.3) and glycerol-3-phosphate dehydrogenase $[\mathrm{NAD}(\mathrm{P})+]$ (EC 1.1.1.94), were also annotated in the whole genome.

\section{Chemotaxonomic Characterization}

The cellular fatty acid (>1\%) composition of strain GR-TSA-9 ${ }^{\mathrm{T}}$ and five closely related strains is listed in Table 2; the most abundant fatty acids of strain GR-TSA-9 ${ }^{\mathrm{T}}$ were $\mathrm{C}_{16: 0}(14.2 \%)$ and summed featured 8 (65.6\%). These results are consistent with those of closely related species within the genus Brevundimonas. However, the amount of some components, such as summed featured 3, $\mathrm{C}_{17: 1} \mathrm{w} 8 \mathrm{c}$, and $\mathrm{C}_{18: 1}$ w7c 11-methyl, differs from the reference strains. The respiratory quinone detected in strain GR-TSA-9 $9^{\mathrm{T}}$ was Q-10, which was consistent with the genus Brevundimonas. The polar lipid profile of strain GR-TSA-9 ${ }^{\mathrm{T}}$ consisted of phosphoglycolipids, phosphatidylglycerol, 1,2-di-O-acyl-3-O-[D-glucopyranosyl$(1 \rightarrow 4)$ - $\alpha$-D-glucopyranuronosyl]glycerol, and unidentified 


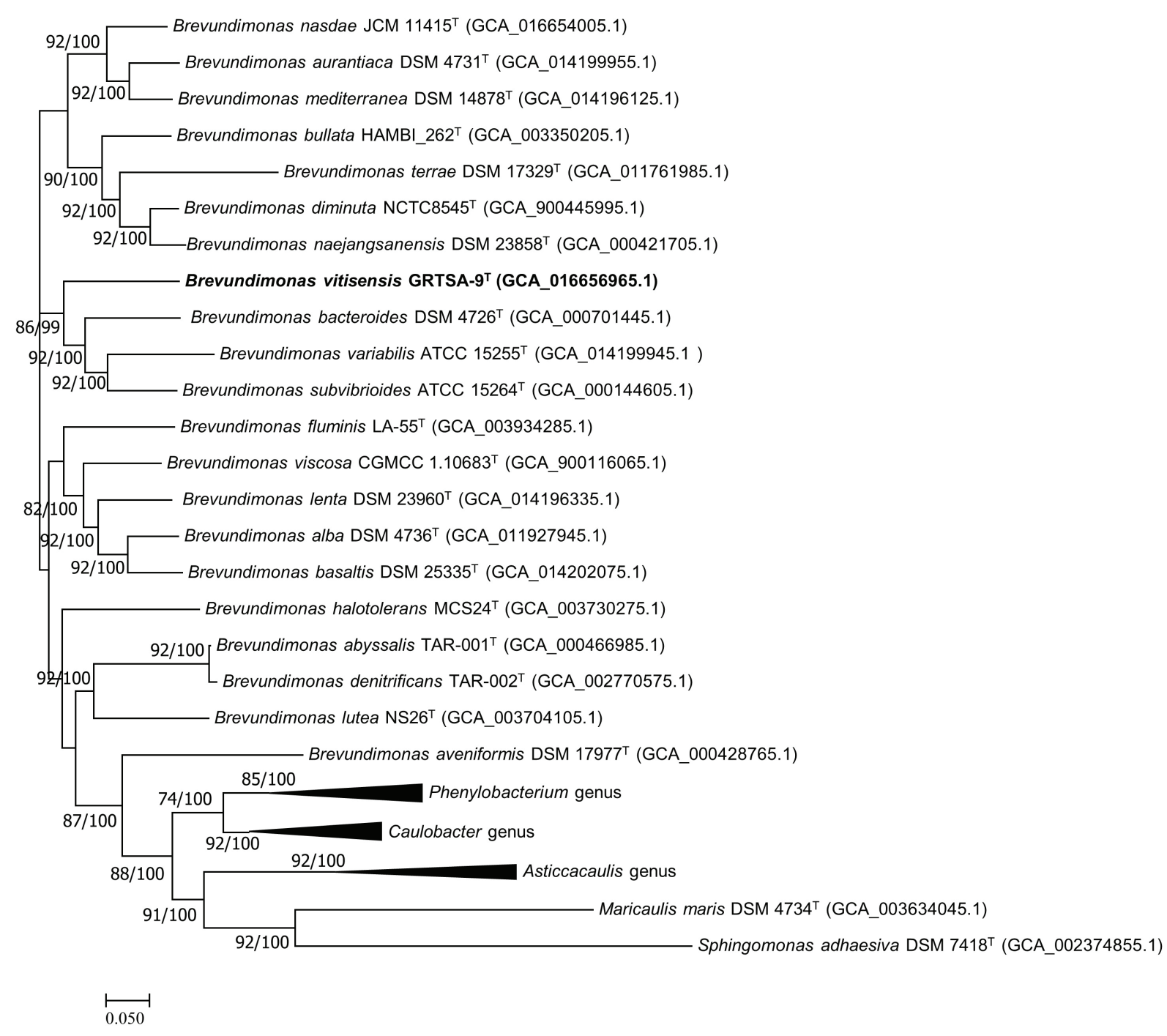

FIGURE 2 | Maximum likelihood algorithm phylogenomic tree based on up-to-date bacterial core gene set (concatenated alignment of 92 core genes) showing the relationship between strain GR-TSA-9 ${ }^{\top}$ and the members of the family Caulobacteraceae. Gene support index (GSI, left) and bootstrap values (right) are indicated at the nodes. Scale bar: 0.050 substitutions per position.

lipids (L1, L2, and L4; Supplementary Figure 4), and lipid spots different from other closely related strains suggested that strain GR-TSA $-9^{\mathrm{T}}$ represents a novel species in the genus Brevundimonas.

\section{Pigment Production}

Strain GR-TSA-9 ${ }^{\mathrm{T}}$ was considered a potential melanin producer on TSA medium and can produce a higher amount of melanin in L-tyrosine-containing medium than without L-tyrosine (Figures 3A,B). On TSA with L-tyrosine, the synthesis of brown pigment was initiated at $3 \mathrm{~d}$ and the pigment increased to brown, dark brown, and blackbrown at 4, 5, and 6 days, respectively. Melanin production in TSB was observed after 3 days of shaking, and at 6 days, the highest yield of melanin $(0.19 \mathrm{~g} / \mathrm{L})$ was obtained (Figure 3C).

\section{Melanin Biosynthetic Pathway via Genomic Annotation}

Strain GR-TSA-9 $9^{\mathrm{T}}$ was found to produce dark brown melaninlike pigment in TSA medium containing L-tyrosine (Figure 3A), suggesting that $\mathrm{L}$-tyrosine is a precursor for melanin biosynthesis in strain GR-TSA-9 ${ }^{\mathrm{T}}$. In addition, it has been reported that Brevundimonas sp. SGJ produces L-DOPA melanin (Surwase et al., 2012a,b, 2013). However, we failed to identify annotated tyrosinases (EC 1.14.18) and laccases (EC 1.10.3.2) with the PGAP and RAST annotation pipelines. These data indicate that melanin synthesis in strain GR-TSA-9 ${ }^{\mathrm{T}}$ may not occur via the L-DOPA melanin biosynthetic pathway. Some interesting features of strain GR-TSA-9 ${ }^{\mathrm{T}}$ were observed HGA-melanin biosynthesis pathway in the whole genome (Figure 4). According to the HGA-melanin synthesis pathway described previously (Hunter and Newman, 2010; Drewnowska et al., 2015; 
TABLE 2 | Cellular fatty acid profiles (>1\%) of strain GR-TSA-9 ${ }^{\top}$ and its closely related species.

\begin{tabular}{|c|c|c|c|c|c|c|}
\hline Fatty acid & 1 & 2 & 3 & 4 & 5 & $6^{a}$ \\
\hline \multicolumn{7}{|l|}{ Saturated } \\
\hline $\mathrm{C}_{14: 0}$ & 0.3 & 1.9 & 1.8 & 0.4 & 1.6 & $1.5 \pm 0.2$ \\
\hline $\mathrm{C}_{15: 0}$ & ND & ND & ND & ND & ND & $1.3 \pm 0.5$ \\
\hline $\mathrm{C}_{16: 0}$ & 14.2 & 19.8 & 15.6 & 11.5 & 18.5 & $30.4 \pm 2.2$ \\
\hline $\mathrm{C}_{17: 0}$ & 1.0 & 0.2 & 5.7 & 7.7 & 1.0 & $1.2 \pm 0.5$ \\
\hline $\mathrm{C}_{18: 0}$ & 0.6 & 0.3 & 0.2 & 0.6 & 1.0 & ND \\
\hline \multicolumn{7}{|l|}{ Hydroxy } \\
\hline $3 \mathrm{OH}-\mathrm{C}_{12: 1}$ & 0.3 & 0.5 & 2.3 & 1.2 & 0.1 & ND \\
\hline $3 \mathrm{OH}-\mathrm{C}_{12: 0}$ & 3.2 & 2.5 & 0.9 & 0.8 & 3.1 & $2.6 \pm 0.4$ \\
\hline \multicolumn{7}{|c|}{ Unsaturated } \\
\hline $\mathrm{C}_{15: 1} \mathrm{w} 8 \mathrm{c}$ & ND & ND & 2.0 & 0.4 & ND & ND \\
\hline$C_{16: 1}$ w7c & ND & ND & ND & ND & ND & $2.2 \pm 0.7$ \\
\hline $\mathrm{C}_{17: 1} w 6 \mathrm{c}$ & 1.9 & 0.3 & 5.1 & 6.0 & 0.8 & ND \\
\hline$C_{17: 1} w 8 c$ & 2.4 & 0.7 & 11.9 & 15.1 & 2.2 & ND \\
\hline $\begin{array}{l}\mathrm{C}_{19: 0} \text { cyclo } \\
\text { w8c }\end{array}$ & ND & ND & ND & ND & ND & $10.1 \pm 3.7$ \\
\hline $\begin{array}{l}\mathrm{C}_{18: 1} \text { w7c } \\
\text { 11-methyl }\end{array}$ & 4.5 & 7.1 & 11.3 & 0.6 & 4.5 & ND \\
\hline \multicolumn{7}{|c|}{ Summed feature* } \\
\hline 2 & 1.7 & ND & ND & ND & ND & ND \\
\hline 3 & 3.0 & 12.1 & 6.0 & 1.3 & 8.1 & ND \\
\hline 7 & ND & ND & ND & ND & ND & $45.3 \pm 6.5$ \\
\hline 8 & 65.6 & 53.5 & 36.1 & 51.3 & 58.3 & ND \\
\hline
\end{tabular}

Values are percentages of total fatty acids. ND, not detected. The major components (>10\%) are shown in bold. Strains: 1, Brevundimonas vitisensis GR-TSA-9'; 2, B. Kwangchunensis KCTC $12380^{\top}$; 3, B. fluminis KCTC $72717^{\top}$; 4, B. viscosa JCM $17426^{T}$; 5, B. lenta KCTC 12871' ; and 6, B. diminuta AJ $2067^{\top}$. All the data were obtained from the present study unless indicated otherwise.

*Summed features are groups of two or three fatty acids that cannot be separated by GLC with the MIDI System. Summed feature 2 contains $C_{14: 0}-3 \mathrm{OH}$ or/and $C_{16: 1}$ iso. Summed feature 3 contains $C_{16: 1}$ w6c or/and $C_{16: 1}$ w7c. Summed feature 7 contains $C_{18: 1}$ w7c, $C_{18: 1}$ w9t, $C_{18: 1}$ w12t. Summed feature 8 was listed as $C_{18: 1} w 7 c$ or/and $C_{18: 1} w 6 c$. a Segers et al. (1994).

Wang et al., 2015), all genes responsible for the HGA melanin synthesis pathway were predicted from the whole genome as follows: araT encoding amino acid aminotransferase (E.E.2.6.1.57) converts tyrosine to 4-hydroxyphenylpyruvic acid (HPP), and $h p p D$ encoding 4-hydroxyphenylpyuvate dioxygenase (EC 1.13.11.27) catalyzes conversion of 4-HPP to HGA. Then, the produced HGA is converted to pyomelanin through autooxidation and spontaneous polymerization. Homogentisic acid is catabolized by a central metabolic pathway that involves three enzymes, homogentisate dioxygenase ( $h m g A$; EC 1.13.11.5), fumarylacetoacetate hydrolase $(h m g B / f a h A), \quad$ and maleylacetoacetate isomerase (maiA/hmgC), and then, final products are fumarate (EC 4.2.1.2) and acetoacetate (AriasBarrau et al., 2004). The pyomelanin production results from a defect in the catabolism pathway (Fonseca et al., 2020). When $h m g A$ levels are low (e.g., gene mutation, deletions, or overexpression of $h m g R$, HGA accumulates and secretes out of cells, and it lead to pyomelanin though HGA auto-oxidation and self-polymerization. (Arias-Barrau et al., 2004; RodríguezRojas et al., 2009; Wang et al., 2011; Fonseca et al., 2020). In the whole genome of strain GR-TSA-9 ${ }^{\mathrm{T}}$, TetR family member $h m g R$ (PA2010), which was previously shown to bind directly to the $h m g A$ promoter and repress $h m g A$ expression, blocks the central pathway and finally accumulates homogentisic acid

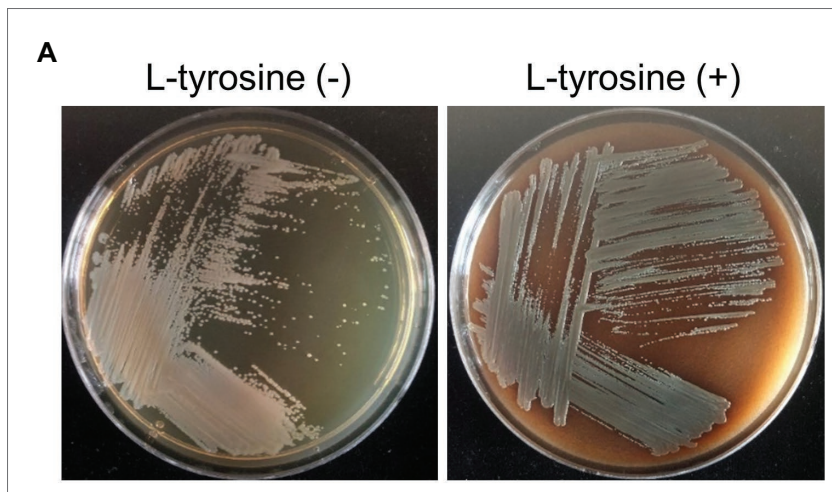

B

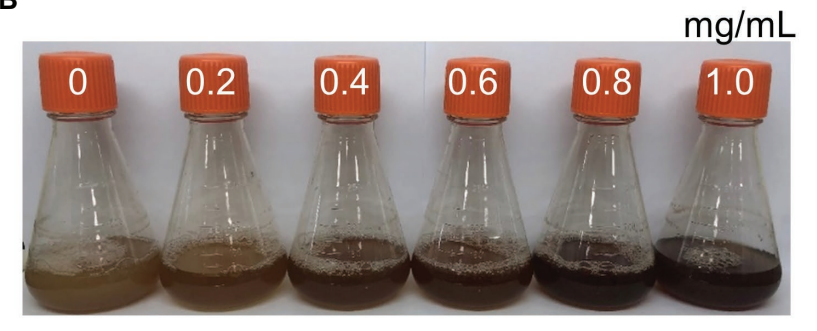

C

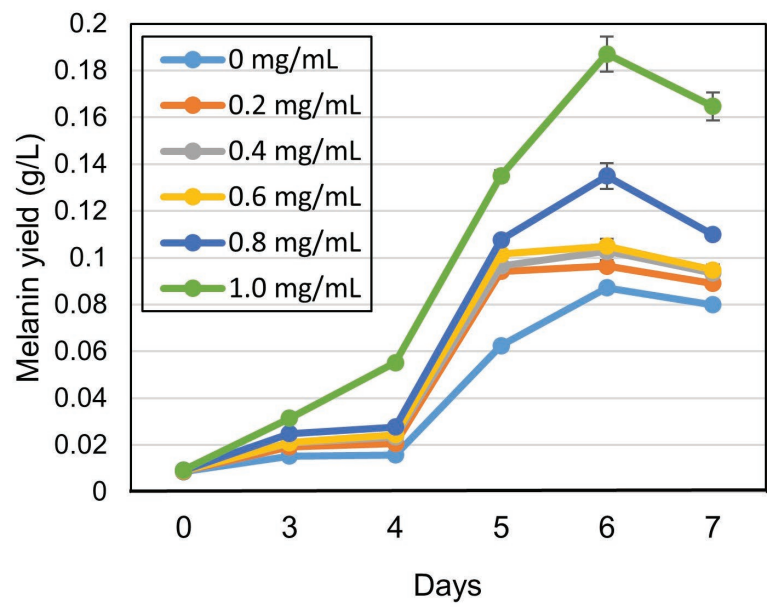

FIGURE 3 | Melanin-like pigment production of strain GR-TSA-9 ${ }^{\top}$ on tryptic soy agar (TSA) medium. (A) Melanin-like pigment production of strain GRTSA-9 ${ }^{\top}$ on TSA without and with L-tyrosine participation; dark brown pigment was produced on the L-tyrosine medium for 5 days. (B,C) Effect of L-tyrosine concentration on melanin production in TSB medium. The graph represents the average of the results from three replicate measurements.

and produces pyomelanin (Figure 4A). In strain GR-TSA-9 ${ }^{\mathrm{T}}$, the gene $h p p D$ (EC 1.13.11.27) encodes the 4-hydroxyphenylpyruvate dioxygenase, araT (EC 2.6.1.57), and fumarate hydratase (EC 4.2.1.2), which share 62.5, 48.6, and $64 \%$ identity with the corresponding protein of Pseudomonas aeruginosa PAO1 (AE004091.2), which was found to produce pyomelanin through the HGA pathway (Bolognese et al., 2019). It is possible that strain GR-TSA-9 ${ }^{\mathrm{T}}$ produces pyomelanin through HGA melanin, which encodes araT, phhR encoding $\sigma^{54}$-dependent transcriptional activator, and $h p p D$, constituting a linear pathway for converting phenylalanine to HGA, which is widely conserved in the genus Pseudomonas (Arai et al., 1980; 
A

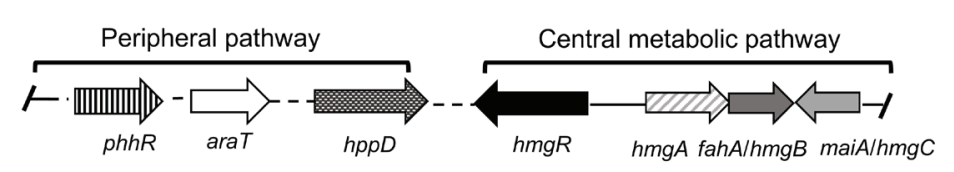

B

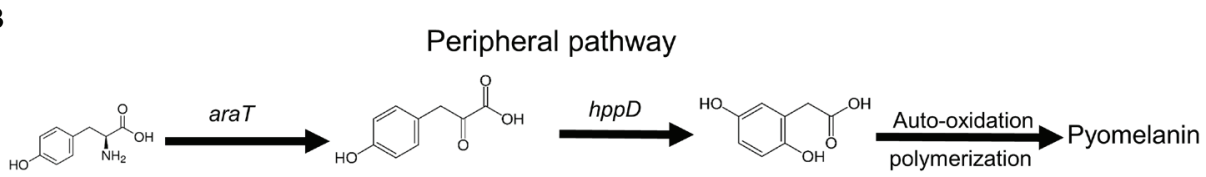

L-tyrosine 4-Hydroxyphenylpyruvic acid Homogentisic acid

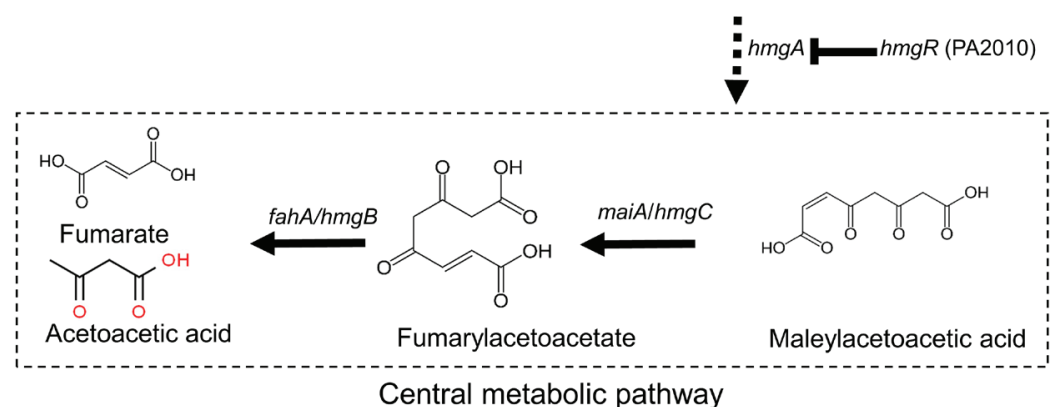

FIGURE 4 | Proposed pathway and gene clusters of pyomelanin biosynthesis in strain GR-TSA-9 (modified from Schmaler-Ripcke et al., 2009). (A) Gene cluster organization and expression of pyomelanin biosynthesis, homogentisate, and central pathways. (B) Pyomelanin biosynthesis and regulation pathway. The enzymes involved are as follows: phhR (JIP62_13420; JIP62_13620; JIP62_02890; and JIP62_0119), sigma-54-dependent Fis family transcriptional regulator; araT (JIP62_09170), aromatic amino acid aminotransferase (EC 2.6.1.57); $h p p D$ (JIP62_07560), hydroxyphenylpyruvate dioxygenase (EC 1.13.11.27); $h m g R$ (JIP62_11565; JIP62_04630; and JIP62_01885), TetR family member transcriptional regulator; $h m g A$ (JIP62_08245), homogentisate dioxygenase; $h m g C / m a i A$ (JIP62_08415), maleylacetoacetate isomerase; and fahA/hmgB (JIP62_RS07590; JIP62_RS08410; and JIP62_RS01250), fumarylacetoacetate hydrolase.

Arias-Barrau et al., 2004; Rodríguez-Rojas et al., 2009; Orlandi et al., 2015; Hocquet et al., 2016; Zeng et al., 2017; Kurian and Bhat, 2018; Bolognese et al., 2019). This suggests that encoding the most critical enzymes 4-hydroxyphenylpyruvate dioxygenase (EC 1.13.11.27), araT (EC 2.6.1.57), and other enzymes such as $h m g R$ annotated in the whole genome demonstrated that the HGA pathway is the melanogenic pathway

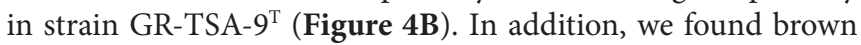
or black pigments in some of the most closely related strains such as B. Kwangchunensis KCTC $12380^{\mathrm{T}}$, B. viscosa JCM $17426^{\mathrm{T}}$, and B. lenta KCTC $12871^{\mathrm{T}}$ strains, but not in B. fluminis KCTC $72717^{\mathrm{T}}$ and $B$. diminuta $\mathrm{AJ} 2067^{\mathrm{T}}$ (Table 1). To determine whether the HGA pathway is specific to strain GR-TSA $-9^{\mathrm{T}}$ or common to the genus Brevundimonas, we investigated the important enzyme-coding genes, such as $h p p D$, araT, and $h m g A$, involved in the HGA melanin synthesis pathway. Our bioinformatic analysis results showed that the key genes related to the HGA-pathway are widely distributed in the genus Brevundimonas, including Brevundimonas naejangsanensis BRV3, Brevundimonas subvibrioides ATCC $15264^{\mathrm{T}}$, Brevundimonas abyssalis TAR-001 ${ }^{\mathrm{T}}$, and Brevundimonas viscosa CGMCC $1.10683^{\mathrm{T}}$. However, the genes phhR and araT could not identify from whole genome of $B$. fluminis KCTC $72717^{\mathrm{T}}$. Although the presence of HGA-melanin-related genes is necessary but insufficient for pyomelanin production (if it cannot block and convert into a central pathway), some Brevundimonas species cannot produce pyomelanin because of the incomplete pathway. Based on these analyses, we suggest that the brown-to-black pigment production in many species in the genus Brevundimonas is because of the production of pyomelanin via the HGA pathway rather than the L-DOPA pathway.

\section{Pigment Characterization}

The wavelength of maximum absorbance was scanned in the range of 200-1000 $\mathrm{nm}$. The wavelength of maximum absorbance of the extracted pigment from the culture supernatant and synthetic melanin standard was observed at $210 \mathrm{~nm}$ (Supplementary Figure 5), which is a typical feature of melanin (ranges between 196 and $300 \mathrm{~nm}$; Surwase et al., 2013; Zeng et al., 2017). The FT-IR spectra were analyzed to confirm that the extracted bacterial pigment was pyomelanin type of melanin. The FT-IR spectra of the extracted bacterial pigment and synthetic pyomelanin standard are shown in Figure 5A. The spectra were recorded at $4000-400 \mathrm{~cm}^{-1}$ using an FT-IR spectrophotometer. Both spectra revealed a broad absorption peak at $3650-3100 \mathrm{~cm}^{-1}$, corresponding to the $-\mathrm{OH}$ group and -NH group. The peaks at 3000-2900 and $1250-1200 \mathrm{~cm}^{-1}$ were attributed to $\mathrm{C}-\mathrm{H}$ groups. The strong absorption peak observed at $1450-1770 \mathrm{~cm}^{-1}$ was ascribed to the $\mathrm{C}=\mathrm{C}$ and $\mathrm{C}=\mathrm{O}$ groups. The peak between 1250 and $1200 \mathrm{~cm}^{-1}$ corresponds to the $\mathrm{N}-\mathrm{H}$ group and $\mathrm{C}-\mathrm{N}$ (secondary amine). The high degree of resemblance in the main absorption peaks indicated 


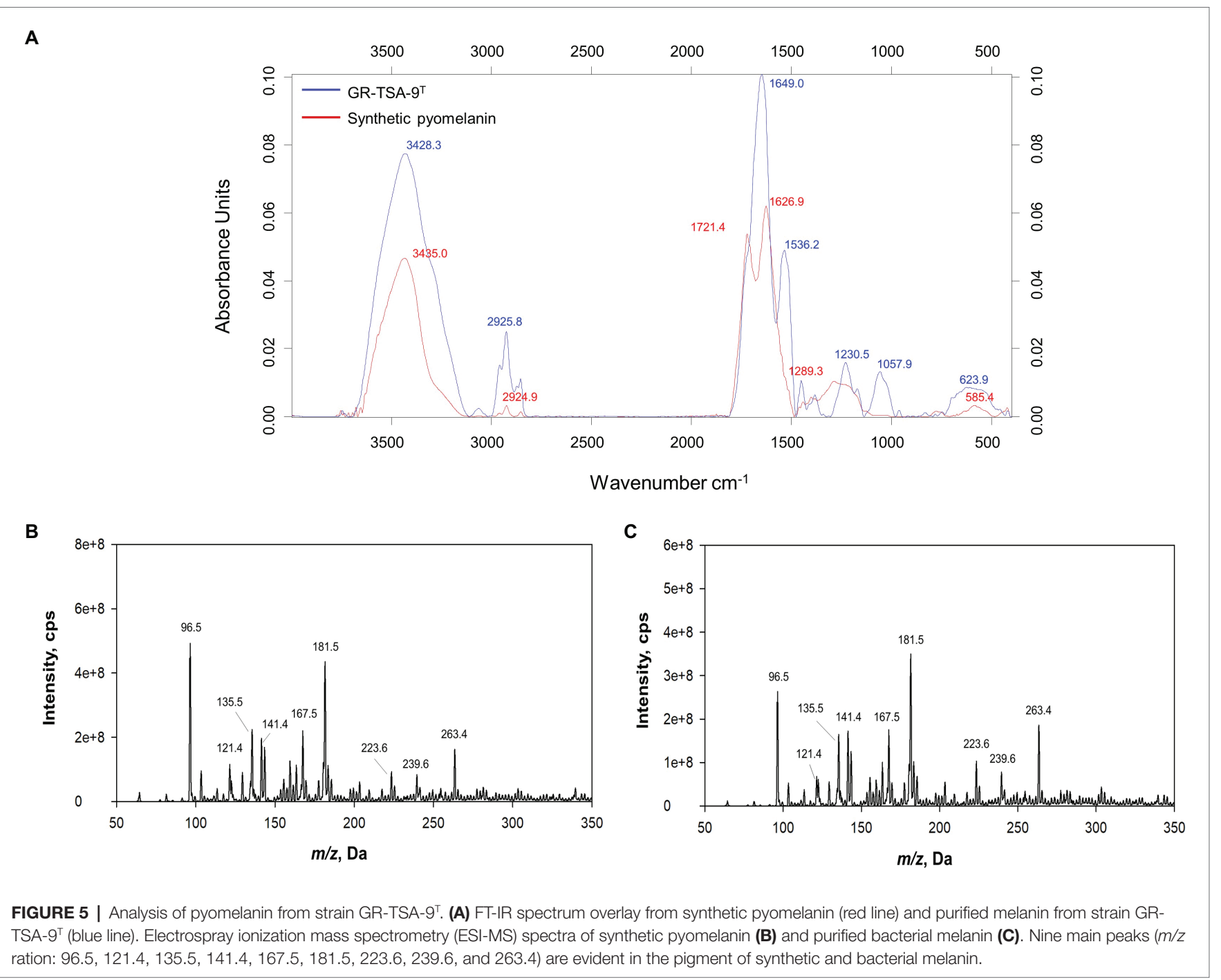

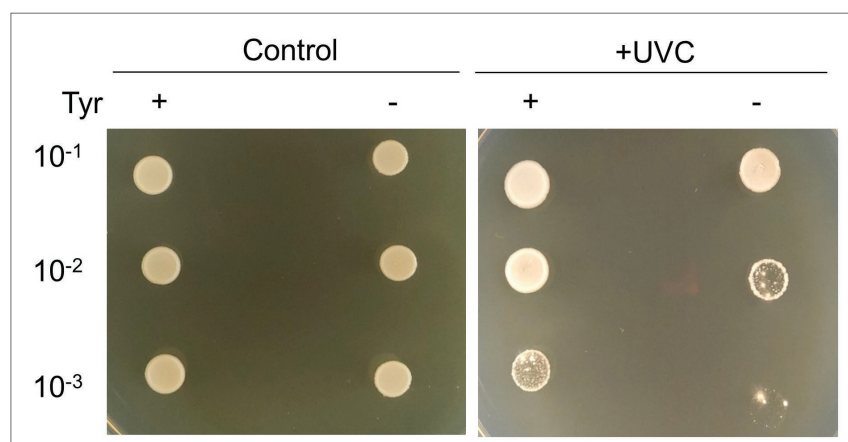

FIGURE 6 | Photoprotective properties of strain GR-TSA-9T. Non-melanized and melanized GR-TSA-9T cells were irradiated with $450 \mathrm{~mJ} / \mathrm{cm}^{2}$ UVC and then spotted in serial dilutions on TSA media for 3 days.

that the pigment isolated from strain GR-TSA- $9^{\mathrm{T}}$ was pyomelanin. Synthetic pyomelanin and purified bacterial melanin were analyzed by ESI-MS. In addition, nine prominent peaks were observed in the mass spectrum of synthetic pyomelanin with $\mathrm{m} / z$ values of $96.5,121.4,135.5,141.4,167.5,181.5,223.6$, 239.6, and 263.4 (Figure 5B). These nine peaks were also detected in the mass spectrum of purified bacterial melanin (Figure 5C). In particular, $\mathrm{m} / z 141.4$ and 263.4 peaks were also detected in a previous report (Singh et al., 2018). These results suggest that the purified bacterial melanin is similar to synthetic pyomelanin.

\section{UVC Tolerance}

To test the photoprotective property of bacterial melanin, cells were irradiated with short-wavelength UVC, which is a damaging type of UV radiation. UVC is absorbed by DNA, resulting in the formation of pyrimidine adducts and strand breaks (Rastogi et al., 2010). The cultured cells on TSA (non-melanized cells) and TSA with $10 \mathrm{mg} / \mathrm{ml}$ L-tyrosine (melanized cells) were irradiated with UVC. The melanized cells grew better than the non-melanized cells after UVC irradiation (Figure 6). This finding suggests that cells grown in melanin-containing media showed significantly higher resistance to UV radiation than those grown on TSA medium alone. 


\section{CONCLUSION}

Together, the results, including phenotypic, physiological, phylogenetic, and biochemical analyses, indicate that strain GR-TSA-9 ${ }^{\mathrm{T}}$ represents a novel member of the genus Brevundimonas. The phylogenetic relationships of strain GR-TSA $-9^{\mathrm{T}}$ and other type strains of the genus Brevundimonas were revealed by phylogenetic trees based on 16S rRNA and core gene sets from the whole-genome sequence. The similarities in physiological characteristics and differences in biochemical characteristics with the closely related strains suggest that GR-TSA-9 ${ }^{\mathrm{T}}$ is a new member of the genus Brevundimonas. The present study is the first to report a type strain in the genus Brevundimonas, which produces pyomelanin. This study provides new insights into the formation and regulation mechanism of melanin, provides the exploration potential of strain GR-TSA-9 ${ }^{\mathrm{T}}$, and paves the way for industrial production in the future. The isolated melanin may have potential applications in the cosmetic and pharmaceutical industries.

\section{Description of Brevundimonas vitisensis sp. nov.}

Brevundimonas vitisensis (vi' tis.ne.sis. N.L. fem. Vitis, the generic name of grapevine, refers to the source from which the bacteria were isolated).

Colonies are grayish white, circular, smooth, and opaque (2-4 mm in diameter) after growth on TSA medium at $25^{\circ} \mathrm{C}$ for 3 days. Brown pigment is found to be a common attribute of melanin production, with optimal growth occurring at $25-30{ }^{\circ} \mathrm{C}$ and $\mathrm{pH} 7.0$ and in $0 \%(\mathrm{w} / \mathrm{v}) \mathrm{NaCl}$. Additionally, strain growth occurs on NA, MA, LB, TSA, and R2A (optimal TSA and LB) but not on PD and RC media. Cells are facultatively anaerobic, gram negative, rod shaped, $(0.2-0.3 \mu \mathrm{m} \times 0.9-2.6 \mu \mathrm{m})$, motile, catalase weak positive, and oxidase positive. In the assay with the API 20NE strips, reactions for esculin hydrolysis and $\beta$-galactosidase are positive, whereas for other substrates are negative. The production of acid is only from salicin. In the API ZYM strips, alkaline phosphatase, esterase (C4), esterase lipase (C8), leucine arylamidase, trypsin, $\beta$-glucosidase, and $\alpha$-glucosidase are positive and valine arylamidase, cystine arylamidase, $\alpha$-chymotrypsin, and naphthol-AS-BIphosphohydrolase are weak positive. The major fatty acids are $\mathrm{C}_{16: 0}(14.2 \%)$ and summed feature $8(65.6 \%)$. The respiratory quinone detected in strain GR-TSA- $9^{\mathrm{T}}$ is Q-10, while the polar lipid profile of strain GR-TSA-9 $9^{\mathrm{T}}$ consisted of phosphoglycolipids,

\section{REFERENCES}

Abraham, W. R., Estrela, A. B., Nikitin, D. I., Smit, J., and Vancanneyt, M. (2010). Brevundimonas halotolerans sp. nov., Brevundimonas poindexterae sp. nov. and Brevundimonas staleyi sp. nov., prosthecate bacteria from aquatic habitats. Int. J. Syst. Evol. Microbiol. 60, 1837-1843. doi: 10.1099/ijs.0.016832-0 Abraham, W. R., Strömpl, C., Meyer, H., Lindholst, S., Moore, E. R., Christ, R., et al. (1999). Phylogeny and polyphasic taxonomy of Caulobacter species. Proposal of Maricaulis gen. Nov. with Maricaulis maris (Poindexter) comb. nov. as the type species, and emended description of the genera Brevundimonas and Caulobacter. Int. J. Syst. Bacteriol. 49, 1053-1073. doi: 10.1099/00207713-49-3-1053 phosphatidylglycerol, 1,2-di-O-acyl-3-O-[D-glucopyranosyl-(1 $\rightarrow 4$ $\alpha$-D-glucopyranuronosyl]glycerol, and unidentified lipids (L1, L2, and L4).

The type strain is $B$. vitisensis GR-TSA-9 ${ }^{\mathrm{T}} \quad(=\mathrm{KCTC}$ $82386^{\mathrm{T}}=$ CGMCC $1.18820^{\mathrm{T}}$ ), isolated from surface-sterilized grapes from Jeongeup, South Korea.

The accession numbers for 16S rRNA and the whole genome of strain GR-TSA-9 ${ }^{\mathrm{T}}$ are MW442968.1 and CP067977.

\section{DATA AVAILABILITY STATEMENT}

The datasets generated for this study are available in the NCBI database. The accession numbers for $16 \mathrm{~S}$ rRNA and the whole genome of strain GR-TSA-9 ${ }^{\mathrm{T}}$ are as follows: GenBank MW442968.1 and CP067977.

\section{AUTHOR CONTRIBUTIONS}

$\mathrm{JL}$ and CK contributed to the conception, supervised the project, and edited the manuscript. LJ, DJ, and JK collected the data and carried out the experiment. LJ and JL wrote the original manuscript and revised the manuscript. YP, JS, JHL, CL, and JP helped with data curation. LJ, DJ, JK, CL, YP, JS, JHL, JP, $\mathrm{CK}$, and JL provided critical feedback of the manuscript. All authors contributed to the article and approved the submitted version.

\section{FUNDING}

This work was supported by the Korea Institute of Planning and Evaluation for Technology in Food, Agriculture and Forestry (IPET) through Agricultural Machinery/Equipment Localization Technology Development Program, the Ministry of Agriculture, Food and Rural Affairs (MAFRA; 321057051HD020), and the KRIBB Research Initiative Program (KGM5282122).

\section{SUPPLEMENTARY MATERIAL}

The Supplementary Material for this article can be found online at: https://www.frontiersin.org/articles/10.3389/fmicb.2021.733612/ full\#supplementary-material

Arai, T., Hamajima, H., and Kuwahara, S. (1980). Pyomelanin production by Pseudomonas aeruginosa. I. Transformation of pyomelanin productivity. Microbiol. Immunol. 24, 1-10. doi: 10.1111/j.1348-0421.1980.tb00556.x

Arias-Barrau, E., Olivera, E. R., Luengo, J. M., Fernández, C., Galán, B., García, J. L., et al. (2004). The homogentisate pathway: a central catabolic pathway involved in the degradation of L-phenylalanine, L-tyrosine, and 3-hydroxyphenylacetate in pseudomonas putida. J. Bacteriol. 186, 5062-5077. doi: 10.1128/JB.186.15.5062-5077.2004

Belgini, D. R., Dias, R. S., Siqueira, V. M., Valadares, L. A., Albanese, J. M., Souza, R. S., et al. (2014). Culturable bacterial diversity from a feed water of a reverse osmosis system, evaluation of biofilm formation and biocontrol 
using phages. World J. Microbiol. Biotechnol. 30, 2689-2700. doi: 10.1007/ s11274-014-1693-1

Bolognese, F., Scanferla, C., Caruso, E., and Orlandi, V. T. (2019). Bacterial melanin production by heterologous expression of 4-hydroxyphenylpyruvate dioxygenase from Pseudomonas aeruginosa. Int. J. Biol. Macromol. 133, 1072-1080. doi: 10.1016/j.ijbiomac.2019.04.061

Chandra, A., Das, A., Sen, M., and Sharma, M. (2017). Brevundimonas diminuta infection in a case of nephrotic syndrome. Indian J. Pathol. Microbiol. 60, 279-281. doi: 10.4103/IJPM.IJPM_679_15

Chun, J., Oren, A., Ventosa, A., Christensen, H., Arahal, D. R., da Costa, M. S., et al. (2018). Proposed minimal standards for the use of genome data for the taxonomy of prokaryotes. Int. J. Syst. Evol. Microbiol. 68, 461-466. doi: 10.1099/ijsem.0.002516

Collins, M., Shah, H., and Minnikin, D. (1980). A note on the separation of natural mixtures of bacterial menaquinones using reverse phase thin-layer chromatography. J. Appl. Bacteriol. 48, 277-282. doi: 10.1111/j.1365-2672.1980. tb01227.x

Drewnowska, J. M., Zambrzycka, M., Kalska-Szostko, B., Fiedoruk, K., and Swiecicka, I. (2015). Melanin-like pigment synthesis by soil bacillus weihenstephanensis isolates from Northeastern Poland. PLoS One 10:e0125428. doi: 10.1371/journal.pone.0125428

Eddy, S. R. (2011). Accelerated profile HMM searches. PLoS Comput. Biol. 7:e1002195. doi: 10.1371/journal.pcbi.1002195

El-Naggar, N. E. A., and El-Ewasy, S. M. (2017). Bioproduction, characterization, anticancer and antioxidant activities of extracellular melanin pigment produced by newly isolated microbial cell factories Streptomyces glaucescens NEAE-H. Sci. Rep. 7:42129. doi: 10.1038/srep42129

Estrela, A. B., and Abraham, W. R. (2010). Brevundimonas vancanneytii sp. nov., isolated from blood of a patient with endocarditis. Int. J. Syst. Evol. Microbiol. 60, 2129-2134. doi: 10.1099/ijs.0.015651-0

Fonseca, E., Freitas, F., Caldart, R., Morgado, S., Vicente, A., and C., (2020). Pyomelanin biosynthetic pathway in pigment-producer strains from the pandemic Acinetobacter baumannii IC-5. Mem. Inst. Oswaldo Cruz 115:200371. doi: 10.1590/0074-02760200371

Fritz, I., Strömpl, C., Nikitin, D. I., Lysenko, A. M., and Abraham, W. R. (2005). Brevundimonas mediterranea sp. nov., a non-stalked species from the Mediterranean Sea. Int. J. Syst. Evol. Microbiol. 55, 479-486. doi: 10.1099/ijs.0.02852-0

Hocquet, D., Petitjean, M., Rohmer, L., Valot, B., Kulasekara, H. D., Bedel, E., et al. (2016). Pyomelanin-producing Pseudomonas aeruginosa selected during chronic infections have a large chromosomal deletion which confers resistance to pyocins. Environ. Microbiol. 18, 3482-3493. doi: 10.1111/1462-2920.13336

Hunter, R. C., and Newman, D. K. (2010). A putative ABC transporter, hatABCDE, is among molecular determinants of pyomelanin production in Pseudomonas aeruginosa. J. Bacteriol. 192, 5962-5971. doi: 10.1128/JB.01021-10

Hwang, S. H., Hwang, W. M., Kang, K., and Ahn, T.-Y. (2018). Gramella fulva sp. nov., isolated from a dry surface of tidal flat. J. Microbiol. 57, 23-29. doi: 10.1007/s12275-019-8370-x

Hyatt, D., Chen, G. L., LoCascio, P. F., Land, M. L., Larimer, F. W., and Hauser, L. J. (2010). Prodigal: prokaryotic gene recognition and translation initiation site identification. BMC Bioinform. 11:119. doi: 10.1186/1471-2105-11-119

Kanehisa, M., Sato, Y., and Morishima, K. (2016). BlastKOALA and GhostKOALA: KEGG tools for functional characterization of genome and metagenome sequences. J. Mol. Biol. 428, 726-731. doi: 10.1016/j.jmb.2015.11.006

Katoh, K., and Standley, D. M. (2013). MAFFT multiple sequence alignment software version 7: improvements in performance and usability. Mol. Biol. Evol. 30, 772-780. doi: 10.1093/molbev/mst010

Kim, M., Oh, H. S., Park, S. C., and Chun, J. (2014). Towards a taxonomic coherence between average nucleotide identity and 16S rRNA gene sequence similarity for species demarcation of prokaryotes. Int. J. Syst. Evol. Microbiol. 64, 346-351. doi: 10.1099/ijs.0.059774-0

Kumar, S., Stecher, G., and Tamura, K. (2016). MEGA7: molecular evolutionary genetics analysis version 7.0 for bigger datasets. Mol. Biol. Evol. 33, 1870-1874. doi: 10.1093/molbev/msw054

Kurian, N. K., and Bhat, S. G. (2018). Data on the characterization of non-cytotoxic pyomelanin produced by marine pseudomonas stutzeri BTCZ10 with cosmetological importance. Data Brief 18, 1889-1894. doi: 10.1016/j.dib.2018.04.123

Lane, D. (1991). "16S/23S rRNA sequencing," in Nucleic Acid Techniques in Bacterial Systematics. eds. E. Stackebrandt and M. Goodfellow (New York: Wiley).
Lee, I., Chalita, M., Ha, S. M., Na, S. I., Yoon, S. H., and Chun, J. (2017). ContEst16S: an algorithm that identifies contaminated prokaryotic genomes using 16S RNA gene sequences. Int. J. Syst. Evol. Microbiol. 67, 2053-2057. doi: $10.1099 /$ ijsem. 0.001872

Lee, Y., and Jeon, C. O. (2017). Cohnella algarum sp. nov., isolated from a freshwater green alga Paulinella chromatophora. Int. J. Syst. Evol. Microbiol. 67, 4767-4772. doi: 10.1099/ijsem.0.002377

Lee, S. A., Kim, Y., Sang, M. K., Song, J., Kwon, S. W., and Weon, H. Y. (2019). Chryseolinea soli sp. nov., isolated from soil. J. Microbiol. 57, 122-126. doi: 10.1007/s12275-019-8562-4

Lee, Y. W., Lee, K. H., Lee, S. Y., and Im, W. T. (2020). Brevundimonas fluminis sp. nov., isolated from a river. Int. J. Syst. Evol. Microbiol. 70, 204-210. doi: 10.1099/ijsem.0.003736

Lee, I., Ouk Kim, Y., Park, S. C., and Chun, J. (2016). OrthoANI: an improved algorithm and software for calculating average nucleotide identity. Int. J. Syst. Evol. Microbiol. 66, 1100-1103. doi: 10.1099/ijsem.0.000760

Meier-Kolthoff, J. P., Auch, A. F., Klenk, H.-P., and Göker, M. (2013). Genome sequence-based species delimitation with confidence intervals and improved distance functions. BMC Bioinform. 14:60. doi: 10.1186/1471-2105-14-60

Na, S. I., Kim, Y. O., Yoon, S. H., Ha, S. M., Baek, I., and Chun, J. (2018). UBCG: up-to-date bacterial core gene set and pipeline for phylogenomic tree reconstruction. J. Microbiol. 56, 280-285. doi: 10.1007/s12275-018-8014-6

Naqqash, T., Imran, A., Hameed, S., Shahid, M., Majeed, A., Iqbal, J., et al. (2020). First report of diazotrophic Brevundimonas spp. as growth enhancer and root colonizer of potato. Sci. Rep. 10:12893. doi: 10.1038/ s41598-020-69782-6

Orlandi, V. T., Bolognese, F., Chiodaroli, L., Tolker-Nielsen, T., and Barbieri, P. (2015). Pigments influence the tolerance of Pseudomonas aeruginosa PAO1 to photodynamically induced oxidative stress. Microbiology 161, 2298-2309. doi: $10.1099 /$ mic.0.000193

Pavan, M. E., López, N. I., and Pettinari, M. J. (2020). Melanin biosynthesis in bacteria, regulation and production perspectives. Appl. Microbiol. Biotechnol. 104, 1357-1370. doi: 10.1007/s00253-019-10245-y

Pham, V. H. T., Jeong, S., Chung, S., and Kim, J. (2016). Brevundimonas albigilva sp. nov., isolated from forest soil. Int. J. Syst. Evol. Microbiol. 66, 1144-1150. doi: 10.1099/ijsem.0.000848

Price, M. N., Dehal, P. S., and Arkin, A. P. (2010). FastTree 2-approximately maximum-likelihood trees for large alignments. PLoS One 5:e9490. doi: 10.1371/journal.pone.0009490

Qu, J. H., Fu, Y. H., Li, X. D., Li, H. F., and Tian, H. L. (2019). Brevundimonas lutea sp. nov., isolated from lake sediment. Int. J. Syst. Evol. Microbiol. 69, 1417-1422. doi: 10.1099/ijsem.0.003330

Rastogi, R. P., Kumar, A., Tyagi, M. B., and Sinha, R. P. (2010). Molecular mechanisms of ultraviolet radiation-induced DNA damage and repair. J. Nucleic Acids 2010:592980. doi: 10.4061/2010/592980

Rathi, M., and Yogalakshmi, N. (2021). Brevundimonas diminuta MYS6 associated Helianthus annuus L. for enhanced copper phytoremediation. Chemosphere 263:128195. doi: 10.1016/j.chemosphere.2020.128195

Rodríguez-Rojas, A., Mena, A., Martín, S., Borrell, N., Oliver, A., and Blázquez, J. (2009). Inactivation of the hmgA gene of Pseudomonas aeruginosa leads to pyomelanin hyperproduction, stress resistance and increased persistence in chronic lung infection. Microbiology 155, 1050-1057. doi: 10.1099/ mic.0.024745-0

Ryan, M. P., and Pembroke, J. T. (2018). Brevundimonas spp: emerging global opportunistic pathogens. Virulence 9, 480-493. doi: 10.1080/21505594.2017.1419116

Ryu, S. H., Park, M., Lee, J. R., Yun, P. Y., and Jeon, C. O. (2007). Brevundimonas aveniformis sp. nov., a stalked species isolated from activated sludge. Int. J. Syst. Evol. Microbiol. 57, 1561-1565. doi: 10.1099/ijs.0.64737-0

Sasser, M., (2006). Bacterial Identification by Gas Chromatographic Analysis of Fatty Acids Methyl Esters (GC-FAME). MIDI Technical MIDI Technical Note \#101 MIDI Inc, Newark, DE, USA.

Schmaler-Ripcke, J., Sugareva, V., Gebhardt, P., Winkler, R., Kniemeyer, O., Heinekamp, T., et al. (2009). Production of pyomelanin, a second type of melanin, via the tyrosine degradation pathway in Aspergillus fumigatus. Appl. Environ. Microbiol. 75, 493-503. doi: 10.1128/AEM.02077-08

Segers, P., Vancanneyt, M., Pot, B., Torck, U., Hoste, B., Dewettinck, D., et al. (1994). Classification of Pseudomonas diminuta Leifson and Hugh 1954 and Pseudomonas vesicularis Büsing, Döll, and Freytag 1953 in Brevundimonas gen. Nov. as Brevundimonas diminuta comb. nov. and Brevundimonas vesicularis 
comb. nov., respectively. Int. J. Syst. Evol. Microbiol. 44, 499-510. doi: 10.1099/00207713-44-3-499

Singh, D., Kumar, J., and Kumar, A. (2018). Isolation of pyomelanin from bacteria and evidences showing its synthesis by 4-hydroxyphenylpyruvate dioxygenase enzyme encoded by hppD gene. Int. J. Biol. Macromol. 119, 864-873. doi: 10.1016/j.ijbiomac.2018.08.003

Singh, N., Marwa, N., Mishra, S. K., Mishra, J., Verma, P. C., Rathaur, S., et al. (2016). Brevundimonas diminuta mediated alleviation of arsenic toxicity and plant growth promotion in Oryza sativa L. Ecotoxicol. Environ. Saf. 125, 25-34. doi: 10.1016/j.ecoenv.2015.11.020

Sofer, Y., Zmira, S., and Amir, J. (2007). Brevundimonas vesicularis septic arthritis in an immunocompetent child. Eur. J. Pediatr. 166, 77-78. doi: 10.1007/ s00431-006-0216-y

Surwase, S. N., Jadhav, S. B., Phugare, S. S., and Jadhav, J. P. (2013). Optimization of melanin production by Brevundimonas sp. SGJ using response surface methodology. 3 Biotech 3, 187-194. doi: 10.1007/s13205-012-0082-4

Surwase, S. N., Patil, S. A., Apine, O. A., and Jadhav, J. P. (2012a). Efficient microbial conversion of L-tyrosine to L-DOPA by Brevundimonas sp. SGJ. Appl. Biochem. Biotechnol. 167, 1015-1028. doi: 10.1007/ s12010-012-9564-4

Surwase, S. N., Patil, S. A., Jadhav, S. B., and Jadhav, J. P. (2012b). Optimization of L-DOPA production by Brevundimonas sp. SGJ using response surface methodology. Microb. Biotechnol. 5, 731-737. doi: 10.1111/j.1751-7915.2012.00363.x

Tatusova, T., DiCuccio, M., Badretdin, A., Chetvernin, V., Nawrocki, E. P., Zaslavsky, L., et al. (2016). NCBI prokaryotic genome annotation pipeline. Nucleic Acids Res. 44, 6614-6624. doi: 10.1093/nar/gkw569

Tsubouchi, T., Koyama, S., Mori, K., Shimane, Y., Usui, K., Tokuda, M., et al. (2014). Brevundimonas denitrificans sp. nov., a denitrifying bacterium isolated from deep subseafloor sediment. Int. J. Syst. Evol. Microbiol. 64, 3709-3716. doi: 10.1099/ijs.0.067199-0

Tsubouchi, T., Shimane, Y., Usui, K., Shimamura, S., Mori, K., Hiraki, T., et al. (2013). Brevundimonas abyssalis sp. nov., a dimorphic prosthecate bacterium isolated from deep-subsea floor sediment. Int. J. Syst. Evol. Microbiol. 63, 1987-1994. doi: 10.1099/ijs.0.043364-0

Wang, H., Qiao, Y., Chai, B., Qiu, C., and Chen, X. (2015). Identification and molecular characterization of the homogentisate pathway responsible for pyomelanin production, the major melanin constituents in Aeromonas media WS. PLoS One 10:e0120923. doi: 10.1371/journal.pone.0120923

Wang, R., Wang, H., Zhou, H., Wang, Y., Yue, J., Diao, B., et al. (2011). Characters of homogentisate oxygenase gene mutation and high clonality of the natural pigment-producing vibrio cholerae strains. BMC Microbiol. 11:109. doi: 10.1186/1471-2180-11-109

Wang, J., Zhang, J., Ding, K., Xin, Y., and Pang, H. (2012). Brevundimonas viscosa sp. nov., isolated from saline soil. Int. J. Syst. Evol. Microbiol. 62, 2475-2479. doi: 10.1099/ijs.0.035352-0

Yoon, S. H., Ha, S. M., Kwon, S., Lim, J., Kim, Y., Seo, H., et al. (2017). Introducing EzBioCloud: a taxonomically united database of 16S rRNA gene sequences and whole-genome assemblies. Int. J. Syst. Evol. Microbiol. 67, 1613-1617. doi: 10.1099/ijsem.0.001755

Yoon, J. H., Kang, S. J., Lee, J. S., Oh, H. W., and Oh, T. K. (2007). Brevundimonas lenta sp. nov., isolated from soil. Int. J. Syst. Evol. Microbiol. 57, 2236-2240. doi: 10.1099/ijs.0.65080-0

Yoon, J. H., Kang, S. J., Oh, H. W., Lee, J. S., and Oh, T. K. (2006). Brevundimonas kwangchunensis sp. nov., isolated from an alkaline soil in Korea. Int. J. Syst. Evol. Microbiol. 56, 613-617. doi: 10.1099/ijs.0.63784-0

Zeng, Z., Guo, X.-P., Cai, X., Wang, P., Li, B., Yang, J.-L., et al. (2017). Pyomelanin from Pseudoalteromonas lipolytica reduces biofouling. Microb. Biotechnol. 10, 1718-1731. doi: 10.1111/1751-7915.12773

Zhang, C., Li, J., An, H., Wu, X., Wu, Y., Long, Y., et al. (2020). Enhanced elimination of dimethachlon from soils using a novel strain Brevundimonas naejangsanensis J3. J. Environ. Manag. 255:109848. doi: 10.1016/j. jenvman.2019.109848

Conflict of Interest: The authors declare that the research was conducted in the absence of any commercial or financial relationships that could be construed as a potential conflict of interest.

Publisher's Note: All claims expressed in this article are solely those of the authors and do not necessarily represent those of their affiliated organizations, or those of the publisher, the editors and the reviewers. Any product that may be evaluated in this article, or claim that may be made by its manufacturer, is not guaranteed or endorsed by the publisher.

Copyright (C) 2021 Jiang, Jeon, Kim, Lee, Peng, Seo, Lee, Paik, Kim and Lee. This is an open-access article distributed under the terms of the Creative Commons Attribution License (CC BY). The use, distribution or reproduction in other forums is permitted, provided the original author(s) and the copyright owner(s) are credited and that the original publication in this journal is cited, in accordance with accepted academic practice. No use, distribution or reproduction is permitted which does not comply with these terms. 